\title{
Aplicación de la teoría y el método sistemático en ciencias sociales
}

\author{
Manuel MARTIN SERRANO
}

Este depósito incluye también la reseña de este artículo escrita por el Prof. Dr. Yves Barel.

\section{REFERENCIA PARA LAS CITAS DE ESTA PUBLICACIÓN Y DE SUS CONTENIDOS:}

MARTIN SERRANO, Manuel (1975): “Aplicación de la teoría y el método sistemático en ciencias sociales", Revista Española de la Opinión Pública, no 42, pp. 81-102. Disponible en: http://www.jstor.org/pss/40182436

Recuperado el_de de 2 de http://eprints.ucm.es/13150/

\section{UTILIZACIÓN DE ESTE DEPÓSITO:}

Usted es libre de copiar, distribuir y comunicar públicamente la obra bajo las siguientes condiciones, que corresponden a la licencia Creative Commons que protege este texto:

Reconocimiento. Debe reconocer y citar al autor original, utilizando la "REFERENCIA PARA LAS CITAS DE ESTA PUBLICACION Y DE SUS CONTENIDOS" (véase recuadro superior).

No comercial. No puede utilizar esta obra para fines comerciales.

Sin obras derivadas. No se puede alterar, transformar, o generar una obra derivada a partir de esta obra. 


\title{
Reading LAS TEORÍAS QUE FUNDAMENTAN LAS METODOLOGÍAS DE INVESTIGACIÓN EN LAS CIENCIAS SOCIALES
}

\author{
Presentación y estudio documental por Daniel Franco Romo
}

En E-Prints se tiene acceso a una selección de la obra original de Manuel Martín Serrano (véase: "Publicaciones de Manuel Martín Serrano disponibles en E-Prints. Selección sistematizada"*, en http://eprints.ucm.es/11107/).

Una parte importante de dicha producción está dedicada al estudio de LAS METODOLOGÍAS DE LAS

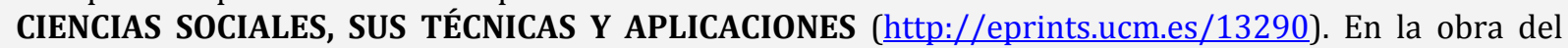
autor, la producción teórica ha ido de la mano de la innovación metodológica; los métodos se han hecho operativos con el desarrollo de nuevas metodologías o la transformación de las existentes; y teoría, métodos y técnicas han sido puestos a prueba para investigar los temas sociales de nuestro tiempo. (En el enlace que sigue, se puede consultar una relación bastante completa y detallada de las investigaciones dirigidas por Manuel Martín Serrano, que están relacionadas con planteamientos teóricos y diseños metodológicos: cf. Publicaciones e investigaciones de Manuel Martín Serrano. Selección).

Las publicaciones referidas al campo de LAS METODOLOGÍAS DE LAS CIENCIAS SOCIALES, SUS TÉCNICAS Y APLICACIONES que se han puesto a disposición de los usuarios de E-Prints se han organizado en dos Reading:

\section{- Reading LAS TEORÍAS QUE FUNDAMENTAN LAS METODOLOGÍAS DE INVESTIGACIÓN EN LAS CIENCIAS SOCIALES, que es el que ahora se está describiendo. \\ - Reading LAS INVESTIGACIONES QUE PRUEBAN LAS TEORÍAS, LAS METODOLOGÍAS Y LAS TÉCNICAS DE LAS CIENCIAS SOCIALES.}

En ellos se han depositado publicaciones del autor en las que teoría, metodología e investigación empírica van de la mano.

\section{Aportaciones de Manuel Martín Serrano a la teoría del método}

La generación de científicos sociales anterior a la de Manuel Martín Serrano estuvo muy interesada en la búsqueda del método que debe poseer todo teórico de las ciencias sociales. El autor se formó en este contexto y sus primeras publicaciones prosiguen en ese empeño. Pero lo hace como un epistemólogo que investiga, es decir: produce teoría del método, con el propósito de renovar los métodos de hacer teoría en el ámbito de las ciencias sociales. Las diferencias entre los métodos de las ciencias naturales y sociales están tratadas en la "Introducción del libro Métodos actuales de investigación social" (http://eprints.ucm.es/13146/). Texto que también hace referencia a otro interés característico de la producción del autor: la vinculación de los métodos con el cambio histórico y con los valores.

En el estudio que hace Chasqui de la renovación metodológica de las ciencias sociales que lleva a cabo Manuel Martín Serrano, se distinguen las siguientes partes:

\section{Creación de metodologías para investigar los sistemas donde interviene la acción humana}

La teoría/metodología que crea y desarrolla Manuel Martín Serrano para trabajar en las ciencias sociales está vinculada a la acción social. Se puede comprobar el alcance de ese giro metodológico para la investigación de los cambios sociales en "Una epistemología de los sistemas finalizados por la intervención humana. El análisis praxeológico de la reproducción y el cambio de los sistemas sociales" (http://eprints.ucm.es/13125/).

El artículo "Perspectivas que ofrecen los nuevos modelos de investigación para las ciencias sociales" (http://eprints.ucm.es/13185/) expone las nuevas aplicaciones metodológicas para el estudio de la acción social.

Finalmente, en "Bases para una epistemología general de las ciencias sociales" ( el autor realiza su propósito de establecer los fundamentos epistemológicos de estas metodologías. 


\section{Reconstrucción y no desconstrucción de los métodos de las ciencias sociales y humanas}

El autor regresa a las fuentes para hallar en ellas las formulaciones originales de los problemas que siguen vigentes para las ciencias sociales. Al poner al descubierto los fundamentos epistemológicos de cada metodología, cabe interpretar mejor sus presupuestos y, si viene a cuento, buscar planteamientos nuevos. Manuel Martín Serrano inicia esta reconstrucción en los mismos años en los que el desconstructivismo propone hacer tabla rasa de toda la herencia teórica y metodológica de las ciencias sociales; pero al margen de dicho movimiento y utilizando el estudio sociohistórico en vez de la retórica. Mencionemos algunos ejemplos de esa reconstrucción:

- "Epistemología del realismo sociológico" (http://eprints.ucm.es/13284/) expone que los sociologismos han incorporado unos criterios de objetividad que son inadecuados para estudiar el cambio histórico de las sociedades. Aclara cómo tienen que ser dichos criterios y el papel que pueden cumplir las utopías en la investigación de las transformaciones históricas.

- "Propuesta de un modelo del espacio y la relación para investigar el cambio social, y aplicación del análisis sociológico del complejo de Edipo" (http://eprints.ucm.es/13174/) es una de las primeras aportaciones de teoría del método del autor, siendo aún muy joven, y de las más originales. Explica que los métodos sociológicos sustituyen al sujeto y sus relaciones por las posiciones que ocupan en las organizaciones; y cómo esas mistificaciones se pueden desvelar y evitar.

- Por la misma época escribe que las ciencias sociales siguen disputadas entre quienes pretenden hacer de ellas el saber aplicado a la interiorización de los roles y estatus, y quienes las entienden como la ciencia crítica que saca a la luz las resistencias que se oponen a la exteriorización de la creatividad y del gozo: "Tratar del placer en ciencias sociales es hablar de la racionalidad y la utilidad de las instituciones sociales y de la veracidad de las teorías sociales del hombre..." (véase en "Las ciencias sociales son las ciencias de la verdad del sujeto", http://eprints.ucm.es/13175/).

\section{Distinciones metódicas que hacen posible diferenciar el campo de la coerción y el campo de la libertad}

Ese empeño de no condicionar el campo de la libertad al campo de la coerción se observa en toda la obra de Manuel Martín Serrano. El autor es uno de los teóricos más críticos con el Formalismo. Pero, precisamente por eso, ha elaborado técnicas para identificar las formas en las que se reflejan las estructuras y el funcionamiento de las organizaciones. Expone que, cuando existen regulaciones en un sistema, siempre hay una forma de representar en un modelo cómo operan. Se pueden transcribir las formas en modelos lógicos y se puede operar con ellos. Por lo tanto, cabe incorporar los análisis lógicos al acerbo metodológico de las ciencias sociales. Haber propuesto y elaborado esas metodologías lógicas es una de las contribuciones más innovadoras de Manuel Martín Serrano. La mediación social (Madrid: Akal, 1977, 2008) es, en gran parte, un libro escrito para hacer posible ese avance metodológico. Una sistematización de estas metodologías y de las técnicas para su aplicación puede encontrarse en "Nuevos métodos para la investigación de la estructura y la dinámica de la enculturización" (http://eprints.ucm.es/13257/).

Las condiciones, las posibilidades y los límites de los nuevos métodos que trabajan con la transformación de los sistemas están explícitas en este depósito ("Aplicación de la teoría y el método sistemático en ciencias sociales"), que incluye también la reseña de este artículo escrita por el Prof. Dr. Yves Barel. Manuel Martín Serrano afirma que ofrecen una integración de las ciencias sociales, a nivel metodológico, en torno a una teoría general de la reproducción y del cambio. Y publica textos destinados a la enseñanza de estas metodologías, que responden al criterio de que "los métodos no pueden sustituir a la teoría ni prescindir de ella, y no pueden ser sustituidos por las técnicas ni carecer de ellas". En E-Prints se han depositado dos "temas" que figuran entre los escritos metodológicos del autor más reproducidos: "Sistema" (http://eprints.ucm.es/14039/) y "Modelo" (http://eprints.ucm.es/14041/).

La utilización que hace Manuel Martín Serrano de los conceptos informacionales y cibernéticos está en el polo opuesto del empleo tecnocrático que suele aparecer en las ciencias sociales. En realidad, cree posible llevar a cabo una apropiación y una transformación de las técnicas cibernéticas por una metodología de inspiración dialéctica. En "Libertad y predicción en las ciencias sociales, analizadas desde una perspectiva 
cibernética" (http://eprints.ucm.es/14040/) muestra que el estado de las metodologías permite que se haga ciencia social con validez histórica. Herramientas que son adecuadas para identificar determinaciones que son revocables, y así seguir avanzando por el largo camino de la antropogénesis. Es en esta perspectiva sociohistórica y antropogenética en la que el autor retoma el paradigma dialéctico y analiza la validez y aplicación que tiene, en el estado actual de los métodos y las herramientas de investigación.

\section{Recuperación y aplicación de metodologías dialécticas}

La dialéctica ha sido la primera metodología que se ha concebido para estudiar el funcionamiento y el cambio en los sistemas sociales donde interviene la acción humana. El autor explica las características específicas del método dialéctico en "La epistemología de la dialéctica social" (http://eprints.ucm.es/13171/), depósito que incluye también la reseña de este artículo escrita por el Prof. Dr. Eloy Terrón. Esas peculiaridades son adecuadas para analizar procesos en los que se contraponen sistemas que están implicados entre ellos y sin embargo obedecen a leyes diferentes. En cambio, no valen para investigar otros sistemas en los que solamente actúen las leyes naturales. Manuel Martín Serrano ha hecho de esta distinción un criterio para saber cuándo viene a cuento utilizar metodologías dialécticas (cf. "Dialéctica, comunicación, mediación", http://eprints.ucm.es/13254/).

\section{REFERENCIAS para enlazar este documento con los que cita y con aquellos que le citan}

- “Acción/comunicación, en las ciencias y en los comportamientos" (http://eprints.ucm.es/13106/)

- "Las relaciones macrosociológicas entre acción y comunicación” (http://eprints.ucm.es/13107/)

- "Sobre la transparencia del método científico" (http://eprints.ucm.es/13250/)

- “Aplicación del método fenomenológico al análisis de la televisión" (http://eprints.ucm.es/11060/)

- "La gesta y la parábola en los relatos de la comunicación pública” (http://eprints.ucm.es/11061/)

- "Los modelos de la mediación se identifican mediante su puesta a prueba con modelos lógicos" (http://eprints.ucm.es/13129/)

- "La estructura de la narración icónica en la televisión. Disertación magistral de Doctorado de Estado en Ciencias y Letras" (http://eprints.ucm.es/11056/)

- "Un método lógico para analizar los significados. Aplicación al estudio del lenguaje de la TV" (http://eprints.ucm.es/13256/)

*Esta selección y sistematización de publicaciones de Manuel Martín Serrano, así como los análisis que les acompañan, se basa principalmente en los estudios realizados por los especialistas que han participado en dos monográficos dedicados a la obra del autor: el primero editado por Anthropos y preparado por Esteban Mate y el segundo por Chasqui, coordinado por Francisco Bernete. También se han localizado y utilizado numerosas reseñas que están publicadas en otras revistas científicas. El investigador Daniel Franco Romo ha planificado y supervisado la ejecución de todo el proyecto. 


\section{Aplicación de la teoría y el método sistemático en ciencias sociales}

\author{
MANUEL MARTIN SERRANO
}

El intento de integrar en un método común las ciencias humanas entre

si, y éstas con las ciencias de la naturaleza, es tan antiguo como la sociologia. Hasta el reciente desarrollo de la lógica de los sistemas informados, aquel empeño no se veía asistido de los útiles necesarios. Los padres fundadores de

la sociologia disponian sólo de modelos particulares en los que apoyar sus esfuerzos integradores, por 10 que su esfuerzo era demasiado ambicioso

y prematuro. El sociólogo que

buscaba el paradigma de la sociedad en la biologia acababa en el organicismo; quien se inspiraba en la economía, cedía al malthusianismo; si buscaba en la ética un modelo, se arriesgaba hacia el finalismo; la físlca le orientaba al determinismo. En la historia de la sociología todos los

intentos de sintesis entre las ciencias de la naturaleza y las ciencias humanas fundadas en la aclimatación de una teoría ajena a las ciencias sociales se ha saldado con un reducionismo. La nueva lógica de

los sistemas se pretende presentar por sus teóricos como el primer método universal que abarce

igualmente el mundo fisico, orgánico y social. La identidad del método preservaría no obstante la diversidad de los objetos.

La sociedad puede ser analizada como un sistema; el organismo también, y tamblén la máquina y la propia naturaleza; aqui se detienen las analogías legitimas. Los sociólogos que adoptan como método el análisis de sistemas, tienen una actitud especifica respecto al objeto de su materia:

a) Están interesados en establecer el repertorio de diferentes estados posibles que puede adoptar el sistema social. Esta actitud les aleia de los positivistas y les aproxima a los estructuralistas y dialécticos.

b) Consideran que

la significación de los datos sociales se refiere a la teoria sistemática que

sirve para organizarlos. Este punto de vista los diferencla de los empiristas y los vincula con los sociólogos del conocimiento de orientación fenomenológica.

Es de notar que la obra de los sociólogos sistemáticos ha renovado el interés por las relaciones entre la sociologia del conocimiento, la teoria

social y el control social. Ha puesto en marcha una nueva lectura de la obra de Comte, con una actitud mucho más comprensiva hacia su intento

de encontrar un método

general que relacionase el sistema social con el sistema cognitivo;

esfuerzo prematuro, pero sin duda, muy pertinente. Igualmente, los sociólogos sistemáticos asumen, desde la nueva perspectiva que ofrece la cibernética, la afirmación de Marx de que toda teorfa sobre el sistema soclal, equivale a un instrumento de control sobre ese sistema. Cabe

afirmar que la teoria de sistemas apllcada en ciencias sociales representa una vuelta a los. objetivos

fundacionales de la "soctólogia a paftic de una teoris y una metodológia que tratamo de explitar 's' sistematizar ent.ensta colaboración.

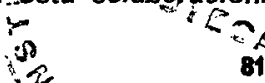




\section{REGRESO AL ANALISIS DE LA FINALIDAD DE LOS PROCESOS SOCIALES}

\section{a) Confusión entre intencio- nalidad y subjetividad en la historia de las ciencias sociales.}

El behaviorismo en psicología y el pragmatismo en sociología redujeron la intencionalidad a un valor subjetivo proyectado por el actor o por el investigador sobre el comportamiento del individuo o del sistema. Desconocieron que existía una intencionalidad objetiva: la capacidad que posee todo sistema de llevar un fin en sí '.

\section{b) Teorías finalistas ante- riores al análisis de sis- temas.}

El predominio de los métodos de investigación no teleológicos en ciencias sociales durante el presente siglo ha sido absoluto. Sin embargo, los psicólogos y sociólogos de formación fenomenológica han continuado preguntando por el fin del comportamiento ${ }^{2}$.

Toönnies es uno de los sociólogos que permanecen fieles a una explica-

\footnotetext{
I La *entelequia de Aristóteles. Hasta el pragmatísmo nunca se había dudado en sociología de que la intencionalidad es un concepto cientifico. En la historia de las ciencias humanas, las explicaciones del comportamiento por el fin, han antecedido a las explicaciones por las causas. Al entender de Aron, el rasgo común de la filosofía de la historia de comienzos del siglo XIX era el carácter finalizado (orientado) de los procesos sociales punto de vista que compartían Tocqueville, Comte y Marx (1964-33).

2 Husserl cree que el conocimiento es intencional. La explicación del ser de las cosas implica la comprehensión de su orientación en el mundo de los restantes objetos (162-81 seq.), tesis en la que le acompañaron Brentano y Heldegger.
}

ción finalizada de la sociedad. Diferencia "el ser de la comunidad « adel ser de las organizaciones " precisamente desde el punto de vista intencional:

- La comunidad es un sistema orientado por múltiples fines, de todos los cuales no posee consciencia.

- La organización persigue conscientemente un fin.

Entre los psicólogos también existen teleólogos. Adler afirma que el sistema anímico es un órgano de ataque $y$ de defensa, preparado para responder a cualquier acontecer, cuya función consiste en preservar al individuo (1962-22). En consecuencia, el comportamiento debe analizarse como si estuviera dirigido hacia una meta. El objeto intencional se pone en claro observando los comportamientos del individuo: a nivel biológico el sistema anímico asegura las funciones de autorreproducción y la seguridad; a nivel psíquico se propone la superioridad sobre el medio y sobre los competidores (1954-34).

Sartre propone un punto de vista aún más drástico sobre el primado del fin en los sistemas biológicos, psíquicos y soćiales:

El comportamiento no está regulado nl por los complejos, ni por los instintos. La personalidad se comprende cuando se descubre la elección original del sujeto. El actor no tiene por qué elegir necesariamente como proyecto vital la superioridad. Su proyecto vital es libre. Incluso puede revocar en cualquier momento su elección original. El proyecto personal está mediatizado por la sociedad, a través de los roles que asigna a sus miembros. Pero la sociedad se presenta para cada cual como una perspectiva de porvenir. Del proyecto elegido por el individuo depende que los roles se acepten o rechacen, se Interioricen o se combatan (1963-90, 147).

El mismo criterio se aplica a las instituciones sociales. Por ejemplo, la rareza de las mujeres de las Islas Marquesas, es una coerción objetiva. Pero la creación de la poliandria es una solución elegida por el sistema social entre las alternativas posibles. La poliandria integra la necesidad en un proyecto social que permite superar una sítuación. El análisis sociológico debe centrarse sobre la intencionalidad, porque 
los hombres se caracterizan por lo que logran hacer con lo que de ellos han hecho las circunstancias (íbid. 86) ${ }^{3}$.

\section{c) Regreso del finalismo a la sociología del consen- so y del conflicto.}

Según Touraine, el pensamiento conservador vuelve a explicar los comportamientos sociales por los fines. Este cambio significa, para el autor, la aparición de una sociología neo-liberal, preocupada por la búsqueda racional de ventajas y por la instrumentación de mecanismos de influencia y de negociación. La ascensión de la nueva sociología se produce a costa del funcionalismo, en trance de verse desplazado como sociología institucionalizada (cf. 1969) ".

A juicio de Lefebvre, la formulación actual del principio de finalidad emplea términos muy próximos a la noción dialéctica de interación y de reciprocidad. Para el análisis dialéctico, toda estructura tiene un fin, que debe ser entendido concretamente como la existencia de una finitud que cada sistema lleva en si mismo. El límite del sistema coincide con su fin, y el fin marca los comportamientos que puede llevar a cabo sin convertirse en otra cosa (cfr. A. C., 1969-186).

El finalismo marxista ha regresado a las ciencias sociales "académicas" por intermedio de la sociología comprensiva de Max Weber. Tanto la sociología de orientación dialéctica como la comprehensiva consideran necesaria la noción de «para qué fin. cuando se explica la acción consciente

3 El existencialismo de Sartre revaloriza el análisis de la intencionalidad de Schopenhaver, quien afirma que todo fin lo es respecto a una voluntad (cf. 1965-82).

- Efectivamente, los funcionalistas han sido antiteleológicos. Conciben el fin como el estado que deviene cuando no hay una voluntad ni una intención. Por ejemplo (señalamos nosotros), Parsons define el fin como a diferencia entre el futuro estado de cosas anticipado, y el que pudiera haberse predicho que se habría derivado de la situación inicial si no hubiese intervenido el actor (subrayado del autor, 1968-1, 88). y sus efectos. Marx afirma que las acciones humanas son siempre intencionales, aun cuando la consciencia sea falsa. Siguiendo a Marx, Weber cree que el significado subjetivo de los fines es un elemento causal de la conducta. La tipología weberiana de la acción social descansa en un análisis de los medios y de los fines. Tanto uno como otro autor afirman que en los sistemas donde se implica la historia, como la propia sociedad, el determinismo es una transgresión metodológica. Según Schaff (marxista y weberiana), ambas teorías de la acción social demuestran que es posible utilizar en sociología la explicación finalista sin incurrir ni en el misticismo ni en el espiritualismo (cf. 1971278 seq).

\section{d) Un método científico pa- ra investigar el "por qué» de los fenómenos socia- les.}

El giro hacia la teleología que se observa en la teoría social es consecuencia de una revolución metodológica. Hoy la finalidad es explicada y no explicativa (cf. Boudon, 1968-35). Los sociólogos pueden volver a preguntar por el "por qué" de los hechos sociales y proponer respuestas operativas falsificables. Ya no necesitan conformarse con una epistemología mecanicista, que está perimida para el resto de las ciencias, ni someter sus investigaciones al criterio de quienes creen que de la sociedad sólo cabe describir el "cómo".

\section{e) En un sistema, toda es. t r u c t u r a determinista equivale a un proceso cuasi-intencional.}

La pregunta por el por qué es ambigua. Denota dos cuestiones: (cf. Piaget, 1967-914). 
Una pregunta sobre las condlclones antecedentes que aclaran el estado del sistema. El comportamiento observable se interpreta como una consecuencia de actos - situaciones pasadas (expllicación causal).

Una pregunta sobre los fines perseguidos por el comportamiento del sistema (explicación teleológica).

La distinción entre "condición" y "fin" del comportamiento de la sociedad desaparece cuando la sociedad se estudia como un sistema diacrónico. El estado del sistema se explica a la vez porque se produjo algún acontecimiento en el pasado y porque cumple ciertas funciones esenciales para la reproducción. El momento que ocupa el observador en el tiempo respecto al fenómeno estudiado determina que vea sus causas desde las consecuencias (explicación teleológica) o desde las condiciones (explicación causal).

Finalidad y determinismo son dos maneras equivalentes de referirse al plan (código, programa) que subyace en todo sistema, y que éste desvela con su funcionamiento en el tiempo. Una acondición" aparece como una restricción del plan que limita el repertorio de fines posibles, controlando los comportamientos efectivos del sistema; a su vez, una "consecuencia aparece como una posibilidad del plan (código, programa) que subyace antecedentes, en los procesos de feed-back. Analizaremos con más detalle el análisis diacrónico de la causalidad en este mismo trabajo.

\section{f) Azar, determinismo y fi- nalismo en el comporta. miento del sistema so- cial: análisis de la tele- nomia.}

Un sistema social está finalizado (es intencional) si puede controlar los valores (uno o varios) que pueden tomar sus elementos. La intencionalidad de los fenómenos sociales está ligada con su automaticidad por retroacciones, que sólo actúan cuando el sistema social se comporta con libertad. La libertad es la condición de la constricción, del mismo modo que la constricción es la condición de la intencionalidad. Esta relación dialéctica equivale al concepto de a organización del sistema social» (cf. Delpech, 1972-128).

Todo sistema donde existe un orden determinista termina creando un orden finalista ( $y$ viceversa). Supongamos la condición determinista más débil: un sistema que recibe del exterior estímulos sin plan, y que inicialmente responde a ellos utilizando al azar su repertorio de respuestas. Se puede demostrar que la simple respuesta a las acciones del exterior determinará un proceso de respuesta estocástico, a partir del cual aparecerá un orden finalizado surgido del azar. Este postulado tiene varias demostraciones materiales ${ }^{5}$, entre ellas alas máquinas que aprenden * las cuales pasan del estado de organismos de respuesta aleatoria, al de organismos con respuesta intencional. Estos organismos cibernéticos, del mismo modo que los biológicos, «ejecutan un plan que ninguna inteligencia ha concebido y tienden a un fin que ninguna voluntad ha elegido. (Jacob, 1970-10). Las relaciones entre organismo y medio, y la teoría de la evolución aparecen con una nueva luz a partir de estas experiencias.

La comprobación de que un objeto posee más de una alternativa para responder al ambiente obliga a admitir que dicho objeto es intencional (según la teoría de los sistemas). Por lo tanto, es inviable estudiar la reproducción y el cambio social excluyendo los fines, excepto en el caso de que

5 Un experimento que demuestra cómo un comportamiento no determinado se transforma en un comportamiento intencional, ha sido llevado a cabo por Frisch, para averiguar cómo se comunican las abejas la existencia de alimento en una dirección y a una distancia determinadas. Las técnicas de investigación de este biólogo están plenas de enseñanzas para el. sociólogo, y son aplicables a los sistemas sociales (1969-190 seq.). 
se crea que la sociedad es una estructura secuencial que responde como un mecanismo.

Todo finalismo es estructurante. La teoría de los sistemas generaliza este postulado que procede de la Gestalt.

\begin{abstract}
Existen numerosas demostraciones: cuando se previene a los individuos de las figuras que deben encontrar en unos dibujos enmascarados, el númeto de identificaciones correctas de las formas se duplica (cf. Guillaume, 1964-86). Lewin demuestra el papel de la Intención como "construct dinámico del campo vitals. La intención diferencia el campo de la percepción y de la acción, y estructura el campo al menos en dos niveles: la aldea directriz» (el fin) y la emanifestación dirigidan (el medio que lleva al fin) (1964, $69,106)$.

El mismo autor ha demostrado que las actividades interrumpidas persisten como fines del comportamiento, en el recuerdo, en tanto que las actividades terminadas se borran pronto.
\end{abstract}

Para referirse a esta forma de estudiar la causalidad se ha adoptado el nombre de atelenomian. Según Piaget, la telenomia representa una revolución epistemológica que ha dejado sin sentido las antiguas querellas entre determinismo y finalidad, $y$ ha establecido un eslabón entre ciencias del hombre y de la naturaleza (1970100).

\section{g) Introducción del principio de indeterminación en ciencias sociales a partir del estudio de la teleno- mia.}

El repertorio de fines que se muestran al investigador cuando estudia un sistema varía en cantidad y tipo según el nivel de análisis que ha adoptado. Un orden a gran escala (por ejemplo, el análisis del sistema social a nivel de las clases sociales] muestra un comportamiento intencional que no explica el comportamiento de ese mismo sistema cuando se analiza a pequeña escala (por ejemplo, la iden- tificación de los fines que persiguen los individuos).

Está bien establecido por la sociología del conocimiento que la escala de observación que adopta el sociólogo crea el fenómeno. Si estudiamos las relaciones de un grupo de trabajo, el nivel de análisis pertenece a la dinámica de grupos; si analizamos las actitudes de los individuos que componen el grupo, el nivel de análisis pertenece a las motivaciones individuales. Las observaciones son distintas y es una transgresión lógica explicar los hechos a un nivel, por las conclusiones obtenidas del estudio a un nivel superior o inferior; del mismo modo que las leyes del movimiento de los átomos no sirven para explicar las leyes de cohesión molecular.

La antigua discusión entre el empirismo y el idealismo sobre la reactividad-constructividad del sujeto cognoscente frente al hecho social, se plantea hoy como el problema de la descentración del observador. Se trata de verificar en qué medida el sujeto que observa los hechos sociales resulta modificado en sus juicios por lo que observa; y en qué medida puede modificar la observación, e incluso el fenómeno, con sus juicios sobre la realidad.

En las ciencias humanas el objeto está formado por sujetos. La descentración se ve dificultada, según Piaget, porque ala frontera entre el sujeto egocéntrico y el sujeto epistemológico, es menos clara cuando el yo del observador es parte integrante de los fenómenos que debería poder estudiar desde fuera” (1970-66).

\section{ESTUDIO ECOLOGICO DE LA SOCIEDAD EN LA SOCIOLOGIA DEL WMWELT}

La teoría de los sistemas es una sociología de las relaciones entre el sistema social y los restantes siste- 
mas con los que establece un intercambio, denominados «el Wmwelt de la sociedadn. Sustituye la teoria clásica de la intracausación de los procesos sociales, cuyo ejemplo más nítido lo ofrece el funcionalismo, por otra teoría de la intercausación.

\section{a) La hipótesis de la intra- causación en ciencias so- ciales.}

Una formulación temprana de la teoría de la intracausación aparece en los darwinistas:

\begin{abstract}
"La primera verdad que yo establezco es que la vida o la muerte de las sociedades procede de causas internas. Buscando un signo que pueda en cada momento denunciarlas, ha hablado de la aptitud para crear la civilización. He dicho que deriva del mérito relativo de las razas» (Gobineau, 1967-121).
\end{abstract}

Durkheim formula el mismo principio como una regla protocolaria:

"La causa determinante de un hecho social, debe buscarse entre los hechos sociales antecedentesn (cf. 1964-125).

Considera, además, que la función de un hecho social debe ser forzosamente social. Estas tesis bien conocidas del primer Durkheim son tenidas por la carta fundacional del funcionalismo. El énfasis en la intracausación de la sociedad, caracteriza a este funcionalismo más que la insistencia en la interacción, que preocupa al funcionalismo anglosajón. Como las mónadas de Leibniz, la sociedad de Durkheim no tiene ventanas, es una entelequia que se mueve a sí misma. Bouthoul considera inútilmente estrecha la regla de que los antecedentes de los fenómenos sociales deban buscarse en otros hechos sociales. No hay razón para que sea asi a priori y siempre. Si otras ciencias hubiesen puesto límites análogos a sus investigaciones, la química jamás se hubiera interesado en la estructura del áto- mo, y la fisiología habria ignorado la química orgánica y celular (1968-98).

La teoría de los sistemas considera que la regla de la intracausación es además de estrecha, falsa. Ningún sistema se mueve a sí mismo sin el concurso de otro distinto. La causalidad supone por definición un extrasistema (un Wmwelt) como describimos con más detalle ${ }^{6}$.

\section{b) Sistema y Wmwelt.}

Cuando se estudia diacrónicamente un sistema hay que considerarlo incluido en otro sistema más general, que cumple la función de Wmwelt'. Esta regla ("postulado de Jacob", 1970) procede del concepto cibernético de cambio: en un sistema todo cambio es un proceso de aintercambio", surgido de la interacción entre el sistema y el marco que le envuelve, o le determina. De tal manera que sólo puede abordarse el estudio del cambio del sistema social respecto al sistema biológico, tecnológico, axiológico, etc.

Ningún sistema $(A)$ puede ser confundido con su Wmwelt (B); ni las constricciones del sistema con las constricciones del Wmwelt. Por ejemplo (proponemos nosotros) si se estudia la familia (sistema A) en la sociedad industrial (Wmwelt B) hay que explicar la demanda de que las mujeres se incorporen al trabajo, y de que se transfiera a la escuela la socialización de los niños, a las exigencias del Wmwelt, comprendiendo que ambos requerimientos no forman parte de las leyes del sistema familiar.

- La hipótesis de la intracausación surgió en los primeros funcionalistas de preocupaciones concretas por los problemas sociales de su época. Sirvió para denunciar la destrucción de las culturas autóctonas por la racionalidad (o la irracionalidad) burocrática de las administraciones coloniales. La existencia de los pueblos administrados peligraban tanto por los "efectos indeseados" de un modelo del progreso, como por los abusos concretos.

7 Se encuentra igualmente la palabra *environnement tanto en autores franceses como alemanes. Ambos vocablos designan el medio exterior con el que intercambia el sistema. 
Ningún sistema puede estudiarse aislado del Wmwelt (B). Recíprocamente el sistema (A) debe ser adoptado como el Wmwelt de (B) cuando este último se estudia como un sistema.

El sistema (A) es alternativamente activo y pasivo (respecto a Wmwelt; el Wmwelt $(B)$ es alternativamente pasivo y activo (respecto al sistema). Se abandona el principio de la inercia en su forma determinista (el sistema esta regido por el Wmwelt) y en su forma voluntarista (el Wmwelt está controlado por el sistema).

En los sistemas rige el principio de la finalización: cada sistema está conectado con su Wmwelt por pautas de interacción, exclusivamente activas en aquellos procesos que son solidarios. La actividad o la pasividad son momentos del proceso existentes para el observador del proceso, y no cualidades de la naturaleza de los objetos. Se dice que el sistema actúa unas veces como determinador (asigna reacciones a los estímulos que percibe) y otras como para-determinador (asigna estímulos a las reacciones que al mismo desencadena). Por su parte, el Wmwelt tiene las mismas características.

El estudio (sociológico, psicológico, biológico) de cada función observada en el sistema, presenta la estructura del objeto de una forma particular, y diferente a la forma que presenta cuando se estudia otra función. Por lo tanto, no existe un punto de vista funcional, ni se puede desarrollar una teoría funcional de los sistemas. Cada teoría describe algunas de las relaciones existentes entre el sistema y su Wmwelt desde el punto de vista que interesa al investigador.

\section{c) Irreversibilidad de los procesos sociales.}

Cuando se estudian los fenómenos sociales como un proceso que afecta, al mismo tiempo, a un Wmwelt y un sistema, no existe posibilidad de que el conjunto "[sistema social-Wmwelt]" regrese al punto de partida. Todo proceso produce una transformación (del sistema, del Wmwelt, o de ambos) incluso cuando el comportamiento del sistema esté orientado a restablecer su condición inicial por un feed-back negativo:

\begin{abstract}
Por ejemplo, si la tecnología del sistema de producción logra mantener constante la tasa de ganancia "reduciendo el tiempo necesario de trabajo (Wmwelt), tanto el trabajo como el sistema de produccíón van a sufrir algunas transformaciones irreversibles: concentración de capitales para afrontar la mayor tasa de inversión en capital constante, mayor divlsión y especialización del trabajo, aumento estacional del desempleo, etc.
\end{abstract}

Este punto de vista del análisis de sistemas es el mismo que caracteriza a la dialéctica" y precisamente aquél en el que la dialéctica y el análisis de sistemas se oponen al funcionalismo. La característica esencial que confiere vigencia al análisis dialéctico de los procesos sociales radica en su capacidad para entender que en los procesos diacrónicos, la constancia del sistema implica el cambio del Wmwelt, y que ambos procesos deben estudiarse solidariamente, perspectiva desde la cual no hay reversibilidad.

\section{d) Conflicto intrasistema e intersistema.}

La diacronía, además de implicar la irreversibilidad del conjunto (sistemaWmwelt) genera en los procesos sociales el conflicto entre la sociedad y su Wmwelt, porque los respectivos ritmos de cambio no son sincrónicos,

8 En la economía competitiva de mercado, el beneficio de la inversión decrece a medida que se avanza en el desarrollo del capitalismo (cf. Marx, 1956-55).

- $Y$ también a las nuevas ciencias físicas a partir de Carnot y Clausius. El tiempo físico se considera irreversible (principios de la termodinámica, que sustituyen las leyes mecanicistas newtonianas por el relativismo einsteniano]. 
incluso cuando existe una interacción armónica entre ambos. Consecuentemente, el equilibrio entre la sociedad y sus instituciones se rompe periódicamente. Veblen dice que las instituciones son producto del proceso pasado, están adaptadas a necesidades pasadas, y nunca están completamente de acuerdo con el presente. El proceso de adaptación progresiva no puede mantenerse a la par del cambio progresivo de las situaciones a las que la comunidad ha de hacer frente. Todo reajuste exige una adaptación posterior, y así sucesivamente (1964).

Huant es un especialista en cibernética que se ha planteado el mismo problema de Veblen, llegando a conclusiones semejantes. Si la sociedad es un sistema, está descartado que sus procesos hagan compatibles la armonía (equilibrio intrasistema) y el ajuste progresivo a los requerimientos del Wmwelt (equilibrio intersistema) puesto que el $W m w e l t$ se modifica tanto más cuanto menos lo haga la sociedad ${ }^{\text {to }}$. Por ejemplo (proponemos nosotros) la persistencia de una organización de la producción no reglada, acelera la degradación del Wmwelt natural por la polución y el agotamiento de los recursos.

\section{ORDEN Y ENTROPIA EN LOS PROCESOS SOCIALES}

\section{a) La energía que mueve la sociedad.}

Las relaciones entre sistema (A) y Wmwelt (B) suponen una fuente de energía, un intercambio de energía, y

10 La supervivencia de la sociedad se logra si, cada vez que las regulaciones funclonales detienen el cambio normativo, la sociedad lleva a cabo la rotura de su equilibrio eligiendo un proyecto que, por definición, es contrario al orden funcional establecido. La rotura del orden como único modo de reproducción social, tiene un costo que Huant mide como * sacrificio del consenso mediante un algoritmo que llama aderivada soclológica (of. 1954; 1967). su transformación. Por ejemplo, entre una comunidad campesina (A) y la naturaleza (B), la naturaleza aporta la energía, transformada por el trabajo comunitario en bienes de consumo. No obstante, sólo una parte de esta energía interesa como objeto de estudio a la sociología. Son las energías que animan los cambios sociales, llamadas energías finas, o más sencillamente, información ":

Se da por supuesto que todos los procesos dinámicos están alimentados 0 energizados. Así, en los procesos de interacción entre un sujeto (sistema A) y su familia (Wmwelt B) cabe referirse a ala libidos energía que ha sido generada, en última instancia, de fuentes biológicas. Pero sólo una parte proporcionalmente pequeña de esa energía se consume como información para coordinar Ja transforma. ción de esta energía en agresión, coope. ración, placer o neurosis. Unicamente la porción de energía destinada a la información determina el acoplamlento (relaciones sociales) entre el sujeto (sistema A) y la familia (Wmwelt B). Cuando el comportamiento de (A) está determinado por algún estimulo procedente de (B), (A) envía a (B) una información sobre los efectos de sus estímulos. Esta Información recibida de (A) actúa a su vez como un estímulo para la posterior reacclón de (B), y asî sucesivamente.

\section{b) Organización y estabili- dad del sistema social.}

Desde los comienzos de la sociología se han tratado de comprender cómo es posible el nivel elevado de complejidad de la sociedad, y de explicar cuáles son los mecanismos que permiten que la organización social, en vez de degradarse, aumente con el paso del tiempo ${ }^{12}$.

"Los estados del sistema social están determinados por las cenergías finas que se destinan a la interacción (información, en términos cibernéticos), frente a las tesis empiristas y organicistas que hacen depender los efectos y las causas de comportamiento del monto global de la energía.

12 Los sociólogos clásicos habían Intuido que la evolución hacia formas de organización más complejas implica una mayor inestabilidad del sistema, o si se prefiere, que un sistema complejo es menos probable. Una lectura moderna de los organicistas permite 
El único modo de remontar la entropía en física, según Maxwell, es ael recurso al diablo". Es decir, el orden se conserva porque interfiere una voluntad y una inteligencia en el acontecer natural. La sociedad está constituida por seres inteligentes y volitivos; puede aceptarse que las intenciones y las previsiones humanas se objetivan en el sistema social como información, recurso que efectivamente se opone a la pérdida del orden.

No obstante, la hipótesis tentadora de describir la sociedad como un sistema informado, no hace su organización menos vulnerable a los inconvenientes de su progresiva complejidad. Si (en términos macrosociológicos) la reproducción de la sociedad ha sido asegurada hasta ahora en el sentido de la progresiva complejidad, deben existir mecanismos sociales capaces de prevalecer sobre la ley de Gibbs ${ }^{13}$.

\section{c) La organización de la so- ciedad transfiere desor- den.}

A nivel holistico (totalidad que incluye la sociedad y el Wmwelt) el conjunto no escapa a la segunda ley de la entropia. La sociedad es un enclave donde crece la organización, respecto a un Wmwelt que evoluciona hacia la ausencia de orden ${ }^{14}$, lo cual significa que la progresiva organiza-

observar que trataban de comprender por qué la sociedad escapa a la ley general de la degradación de la energía. Esta idea se corresponde con la segunda ley de la termodinámica y aparece explícitamente en Comte antes que en Levi-Strauss (cf. Martín Serrano, 1975).

13 La Ley de Gibbs dice que un sistema, a medida que avanza en el tíempo, tiende a desorganizarse, si ninguna otra acción se opone a la entropia.

it Lo mismo ocurre con la vida. El tema ha sido muy bien estudiado en lo que respecta a los organismos biológicos por Monod (1970), y por Meyer y Ulmo, en la obra colectiva dirigida por Plaget (1967 b). ción social supone un crecimiento transferido de desorden a otros sistemas con los que cada sociedad está interrelacionada. Ahora interesa anotar que no es posible explicar la posibilidad de la existencia del orden social, ni la evolución de la organización que le expresa, a partir de la dinámica interna al sistema social. Se puede invertir la tesis funcionalista, diciendo que la sociedad persiste y crece en el orden precisamente porque es un sistema desorganizador (del Wmwelt).

Levi-Strauss indica que las sociedades civilizadas fabrican mucho orden en el sistema tecnológico (por' ejemplo, el maquinismol. Pero también fabrican mucha entropia, que transfieren al Wmwelt social (conflictos, luchas políticas, etc.). Cuando el Wmwelt desordenado se nivela (por ejemplo, con la democracia liberal\} el desorden se transfiere, amplificado, a un nuevo Wmwelt: por ejemplo, a los pueblos colonizados: "(La civilización) ha tenido que buscar constantemente en el seno mismo de la sociedad, 0 a través del sometimiento de los pueblos conquistados la realización de un desnivel» (1968-36). Este autor afirma que la civilización no es otra cosa que un mecanismo complejo destinado a oponerse a la entropía, y que la ciencia que la estudia, es una aentropología más que una antropología; ciencia especializada en estudiar la integración-desintegración (1970-417).

\section{d) Forma en que la socie- dad asegura su reproduc- ción: los subsistemas generadores de orden.}

Los autores que analizan la sociedad como un sistema coinciden en que la orientación de la sociedad hacia una complejidad creciente está asegurada por estructuras intermedias, situadas entre los componentes elementales y el propio sistema. Están afirmando que no existe ni una reproduc- 
ción de los componentes, ni una reproducción de la totalidad social; y por lo tanto, se oponen tanto a la teoría orgánica del consenso como a la empirista ${ }^{15}$.

Estas observaciones permiten una lectura moderna de los sociólogos que han destacado el papel de las instituciones intermedias, como mediadores entre el consenso y la complejidad social. Recordemos el papel que Comte concedía a la Religión Positiva, Spencer a las instituciones militares, Durkheim a las asociaciones laborales y Pareto a las élites. La idea de Nadel, de que en la sociedad existen subgrupos generadores de complejidad $y$ reproductores de estabilidad (por ejemplo, la familia), sugiere un análisis parecido desde una perspectiva funcional (cf. 1970-122). Del mismo modo, la distinción de Gurvitch entre clases sociales y agrupamientos particulares, ofrece una interesante corrección al holismo dialéctico (1962185 seq.).

Touraine se ocupa de la identifìcación de los subsistemas que reproducen y aumentan la complejidad social. $\mathrm{Ha}$ construido una teoría social de las formas de acción y de las estrategias que caracterizan a las sub-organizaciones, que presenta como un "acciona. lismon (cf. 1965). Este autor ve en el trabajo la fuente de la complejidad social, y la expresión de la intencionalidad del sistema, puesto que es en el trabajo donde los valores son transformados en actos; y por medio del trabajo se aseguran las dos funciones de la reproducción social: la creatividad y el control de la organización para evitar la degradación del orden. En las sociedades industriales la creatividad y control del sistema se explicitan como "desarrollo" y "de-

15 Según Koester son los subsistemas que integran el sistema social los que se reproducen. Este autor afirma que la progresión hacia la complejidad es mucho más rápida cuando resulta de la integración entre los subsistemas que componen la sociedad, que cuando procede de la evolución del sistema global (1968-63 seq.). Por otra parte, un sistema diferenciado en subsistemas jerarquizados es mucho más estable que un sistema no diferenciado. mocracian (el primero, recreación del sistema por el trabajo; el segundo, control institucional que da garantias a las minorias y somete a los dirigentes). Touraine afirma que estos subsistemas explican la integración y la progresiva complejidad de las sociedades industriales, y que son los fundamentos de su carácter dirigido ${ }^{16}$.

\section{f) Análisis del cambio en la teoría de sistemas.}

Algunos autores explican el incremento de la complejidad de la organización social por el cambio cualitativo de sus generadores de orden:

\footnotetext{
Por ejemplo (proponemos nosotros), la diferenciación entre el orden de la naturaleza y de la cultura, primeramentel se ha preservado aislando unos sterritorios" (zona de caza, zona de habitación). En esta fase histórica el generador de orden era un subsistema cuasi-biológico, como el de los animales. Posteriormente interviene un subsistema tecnológico (el poblado, la explotacíón agrícola] y actualmente, el orden se genera por un subsistema cuasi-informacional (las comunicaciones y los intercambios en una sociedad urbanizada).
}

La evolución de la sociedad no estaria orientada solamente hacia la progresiva especialización como suponía Spencer, ni hacia la integración creciente, como creía Durkheim en su etapa funcionalista. Las propias formas de control de la evolución estarían sujetas a evolución histórica.

El cambio histórico de los generadores de orden aclara la distinción de Levi-Strauss entre sociedades frías $y$ calientes (términos equivalentes a entropía alta y bajaj. La separación de Moles entre sistemas de orden próximo y lejano, y la de Mcluhan entre formas de interacción cálidas y frías, proceden del mismo núcleo de ideas.

16 Otro aspecto del análisis de Touraine, que ahora no es pertinente, se refiere a las relaciones entre integración y alienación. En tales sociedades la marcha hacia la complejidad supone una triple alienación (técnica, burocrática y política). 


\section{g) Integración de las cien- cias sociales en una teo- ría general de la repro- ducción y el cambio.}

La teoría de los sistemas tiene su objeto más característico en el cambio sincrónico y diacrónico de los generadores de orden: tanto aquellos que actúan a nivel de las instituciones, como de la personalidad y el conocimiento. El carácter general del método que emplea, y la universalidad de los postulados de los que parte, explican que tenga poco interés en separar el estudio del Sistema social respecto al estudio del Sistema de la personalidad, y el Sistema de valores. O lo que es lo mismo: $\mathrm{La}$ psicología social, la sociología de las instituciones, y la sociología del conocimiento, tratan de integrarse en una misma ciencia social de las formas de la reproducción y el cambio.

La ambición de la nueva metodologia consiste en explicar el control y la creatividad, el consenso y el conflicto, en el sistema y en el proceso, con un mismo método, que aborde tanto la sincronía como la diacronía. La próxima parte de nuestro trabajo se ocupa de sistematizar sus postulados.

\section{LAS HIPOTESIS DE LA TEORIA DE LOS SISTEMAS}

\section{a) El sistema social no es sumativo.}

Existe un sistema cuando la totalidad es más compleja que la suma de sus elementos:

Así, los miembros de la tripulación de una astronave constituyen un sistema; la modificación de uno de los componentes modifica a los demás, o al sistema entero; el conjunto es coherente e Indivisible (desde el punto de vista del gobierno de la nave). En cambio, la nube de langostas no es un sistema; unos componentes so comportan con independencia de los otros, y pueden ser sumados o separados, sin que el conjunto ni los otros componentes sean afectados.

La no-sumatividad de los componentes de un sistema es una idea bien conocida en Psicología desde la Gestalt. En Sociología y en Psicología social el tópico se ha invocado más que aplicado. Incluso Moreno y Lewin explican la estructura de la interacción como el resultado de las conexiones intercambiadas entre unidades más elementales (por ejemplo, aroles" o "subcampos"]. La teoría general de los sistemas destaca que la configuración ya existe en la interacción; no puede ser separada de ella ni considerada su producto.

\section{b) La medida de la comple- jidad es el método de las ciencias sociales.}

La medida de la complejidad de la estructura, y de la complejidad del funcionamiento de los procesos, permite estudiar los sistemas como totalidades. La complejidad es una medida universal, aplicable a los análisis sincrónicos y diacrónicos. El método para medir la complejidad ha sido desarrollado por von Neumann a partir de la teoría de la comunicación. Este autor ha hecho uso del citado método en economía (1953). En Psicología social se ha utilizado por Moles para analizar los comportamientos de los grupos (1964).

La medida de la complejidad de la estructura, 0 análisis de la complexión de un sistema con fines predictivos, es conocida con el nombre de a teoría de los juegos" y "matemáticas de la decisión" (cf. Fishburg, 1973). La medida de la complejidad del funcionamiento del sistema, o análisis de su creatividad se denomina "matemáti- 
cas de las estructuras informadas» (cf. Moles, 1972).

Esta no es la ocasión de detenerse en las técnicas de los nuevos métodos. En esencia, estudian, por medio del análisis probabilístico, los comportamientos del sujeto y del grupo que hasta ahora se creían sólo explicables por un modelo determinista de la acción. La libertad de respuesta del objeto frente a las diferentes situaciones es compatible con la predicción de los estados probables que va a adoptar ante ellas. A juicio de Wiener, estos métodos de análisis de la complexión han revolucionado ya la teoría social, y probablemente van a transformar la práctica social (1971-445).

La "totalidad" que sirve de marco al análisis del sistema es una realidad concreta estructurada y no un concepto vacio. En este punto la teoría de los sistemas satisface tanto las exigencias de los adversarios del holismo (cf. Popper, 1957) como de los dialécticos (cf. Kosik, 1970).

\section{c) La constricción genera el sistema social y puede ser traducida a un códi- go lógico.}

Existe un sistema cuando sus componentes no pueden adoptar todos los estados posibles que cabe imaginar desde un criterio aleatorio.

El sistema se distingue del agregado porque está sujeto a constricción estructural o funcional (prohibiciones, incompatibilidades, etc.). La constricción hace posible la predicción del comportamiento del sistema, porque impide que sobrevengan todos los estados posibles que los componentes pueden adoptar, si se tienen en cuenta exclusivamente criterios aleatorios de integración.

Todas las constricciones generan orden. El orden se expresa con el término "código". La función de los códigos resulta particularmente evidente en las relaciones sociales pautadas: por ejemplo, en las reglas de la exogamia, gracias a las cuales los an- tropólogos pueden prever la clase de relaciones sexuales, económicas y de poder que existen entre los hijos, los padres, y los tíos maternos en cada sociedad.

\section{d) El tamaño de un sistema es una función de sus grados de libertad.}

La complejidad del sistema depende de la medida en la que pueda ser controlado y definido integramente y no del número de sus componentes.

Un sistema con pocos miembros. por ejemplo una familia, es un sistema muy grande cuando puede adoptar un número indefinido de estados nopredecibles. Un sistema con muchos componentes, en el que todos los elementos son idénticos e independientes, como una carrera ciclista, es un sistema pequeño (cf. Ashby, 1960). La complejidad se entiende como una función de los grados de libertad que puede adoptar el sistema, punto de vista que independiza la medida de su contenido.

\section{e) La diacronía invalida el análisis de la causalidad.}

En un sistema integrado se excluye la explicación de la interacción como el efecto unilateral de A sobre $B$. Desde el punto de vista de la totalidad, $A$ afecta a $B$ en el momento $t_{1}$, pero la reacción de $B$ sobre $A$ en el momento $t_{2}$, transforma a este último elemento de paciente en agente. Las explicaciones causales de la relación entre elementos son un artificio producido por la puntuación temporal que dé el observador a los procesos ${ }^{17}$. Un ejemplo lo sugiere la

17 Michotte (1954) ha demostrado que la percepción del orden que permite distinguir la causa del efecto depende de la organización cognoscitiva del sujeto (de su evisión del mundox], mediante un ingenioso experimento con rectángulos móviles. «a experiencias que genera el concepto de causación es interior $y$ no exterior al sujeto. 
pelea verbal entre dos personas: cada uno de los actores adopta en la interacción sucesivas posiciones de agresión-repliegue.

\section{f) Sólo la perspectiva dia- crónica (análisis de la mutación) permite en- tender la invarianza.}

La propia idea del sistema social implica su duración (cf. Bentalanffy, 1969).

Este punto de vista invierte «la regla de oro" del método estructural, expresada por esta frase de Hjelmslev: "la existencia de un sistema no presupone la existencia de un proceson (1971-56). La invarianza del sistema remite a hechos recurrentes en el tiempo y no a hechos eternamente idénticos. Por ejemplo (proponemos nosotros): El Capital (D) se reproduce en la circulación $(\rightarrow)$ transformándose en mercancía (M), de acuerdo con la conocida fórmula de Marx:

$$
\mathrm{D} \rightarrow \mathrm{M} \rightarrow \mathrm{D}
$$

En el sistema de mercado es invariable la recurrencia (forma de circulación del Dinero) precisamente porque los componentes del sistema cambian en el proceso.

\section{g) Sólo la perspectiva sin- crónica (análisis de la forma) permite compren- der la mutación.}

La idea de proceso implica la permanencia; la idea de cambio cualitativo, la reproducción invariante. El cambio puede producir tanto una replicación de los componentes del sistema como una selección o una mutación; por lo que la cualidad del cambio no puede deducirse de la diacronía (cf. Lefebvre, 1969-52).

\section{h) En la sociedad la causa eficiente es una causa fi- nal ( $y$ viceversa).}

Sólo los sistemas cerrados y aislados están determinados por sus causas de partida.

Las ciencias sociales estudian generalmente sistemas abiertos o semiaislados. En ambos tipos de sistemas la referencia a sus causas iniciales no explica los estados que adopta el sistema:

La característica funcional de los sistemas abiertos consiste en que se independizan de las condiciones iniciales que les han generado, para estar determinados solamente por sus propios parámetros. La población se analiza frecuentemente como un sistema abierto ${ }^{18}$. Las mismas consecuencias (por ejemplo, la sobrepoblación) pueden derivarse de distintos orígenes (una creencia religiosa, la disminución de la mortalidad infantil, etc.) $y$ efectos distintos pueden originarse en una misma causa (por ejemplo, las distintas consecuencias de la generalización de anticonceptivos en países desarrollados y subdesarrollados).

En ciencias sociales se presentan, con mayor frecuencia, sistemas semi-aislados, caracterizados porque están en relación con el resto de los sistemas a través de uentradas» $y$ de «salidas» específicas. La distribución de las rentas es un sistema semi-aislado.

La evolución de los sistemas abiertos y semi-aislados no está orientada por una finalidad exterior al propio sistema. La intencionalidad ( $\sin$ la determinación) se considera tan inadecuada como la causalidad (sin la intencionalidad) para explicar el funcionamiento de la sociedad. La teoría de los sistemas unifica ambos conceptos en el interior de "sistemas de determinaciónn.

Existen dos sistemas generales de determinación: el control circular y el control retroactivo del sistema, en cuyo marco la causalidad y la finalidad son casos límites.

La querella sobre el origen de la causación entre deterministas y fina-

18 Los sociólogos que siguen a Malthus, discrepan de esta interpiretación y se inclinan a ver en la población un sistema semi-aislado. 
listas se diluye, porque en el sistema social la finalidad está causada y la causa está finalizada.

\section{i) La estabilidad de una or- ganización compleja no se opone a la existencia del conflicto, sino que lo supone.}

Tal vez el mayor aporte de la teoría de los sistemas reside en haber ter. minado con la separación entre equilibrio y conflicto. Los cibernétícos demuestran que todo sistema abierto y autoorganizado subsiste necesariamente en una situación de conflicto (cf. Wiener, 1948; Fortet, 1967). En el sistema social se generan invariantes que lo regulan para adaptarse al conflicto (por ejemplo, las normas y los estereotipos); y el conflicto surge porque existen invariantes en el sistema. Autorregulación y conflicto son mecanismos solidarios. La autorregulación puede ser entendida como la transformación de los dinamismos externos al sistema en dinamismos internos al sistema (cf. Barel, 1973-287) y la crisis, como la transformación de las invariantes internas, en constricciones externas, tal como sugería Marx en el análisis de la superproducción (1972). Se ha abierto la vía a una integración entre la dialéctica $y$ el estructuralismo genético o funcional.

\section{MODELOS DEL FUNCIONAMIENTO DEL SISTEMA SOCIAL}

\section{a) Formas que adopta la so- ciedad cuando opera co- mo un sistema de inte- gración.}

Un sistema se caracteriza porque sus respuestas a los estímulos están controladas en parte por la estructura de reacción que les es propia, razón por la que su comportamiento no depende rígidamente de la naturaleza del estímulo.

La teoría de los sistemas aplica el método de la "caja negra " para investigar el comportamiento de la sociedad. Observa los estímulos que recibe el sistema social por sus "entradas" $y$ las reacciones que se observan en "las salidas", sin emplear ninguna hipótesis inicial sobre la estructura del sistema ni sobre la naturaleza de los estímulos que va a intercambiar el sistema con el medio. El método de "la caja negra" presupone que la sociedad es un mediador que actúa como un sistema de integración, abierto tanto a los estímulos como a las respuestas. La teoría de los sistemas cuenta con tres modelos diferentes de mediadores:

- Cabe interpretar que la sociedad responde a los estímulos como un sistema de conjunción cuando es necesario que se activen varias entradas para que se produzca una salida. La explicación que propone Max Weber de la génesis del capitalismo presupone un sistema de conjunción.

- Se pueden explicar algunas respuestas sociales como caracteristicas de un sistema de alternación cuando cualquier estímulo en cualquier entrada desencadena una respuesta. El modelo de "los frenos biológicos" de Malthus es un ejemplo.

- También existen casos en los que la sociedad opera como un sistema replicante cuando un sólo estímulo a la entrada se reproduce por varias salidas. Ocurre en los procesos de información.

Interpretando la sociedad como un sistema mediador se ha abierto un nuevo método, aplicable a un nuevo objeto: el análisis de los modelos de integración que intervienen en los procesos de control social y de cambio.

\section{b) Examen de la concepción funcionalista de «integra- ción".}

Una gran parte de los sociólogos neofuncionalistas sugieren la hipóte- 
sis de que la sociedad es un sistema retroactivo (por ejemplo, Nadel, 1970).

En realidad, el comportamiento de la sociedad frente a los distintos acontecimientos permite ilustrar toda la gama de sistemas de respuesta conocidos:

- Como afirman Nadel y los funcionalistas, frecuentemente la sociedad opera como un sistema a reacción negativa (sistema autorregulado). La respuesta compensa la acción del estímulo (feed-back). Por ejemplo, el suicidio egoista, en la forma que lo describe Durkheim, es una defensa del sistema social frente a la pérdida del consenso.

- La sociedad opera como un sistema a reacción positiva, cuando responde a los estímulos amplificándolos. Por ejemplo, la violencia suele generar en todos los sistemas respuestas aún más violentas. Esta forma de organización es transitoria si corresponde a una fase de desequilibrio, e irreversible si corresponde a una etapa revolucionaria de la que va a generarse la destrucción del sistema.

- La sociedad conjuga a veces respuestas amplificativas y retroactivas. Nadel ofrece la teoría del refuerzo de la normalidad y el castigo de la desviación como un ejemplo que incluye un feed-back positivo y otro negativo (op. cit., 88).

Definir la sociedad como un sistema retroactivo es un avance teórico muy nimio. De hecho es un truismo, porque efectivamente la homeostasis (feed-back negativo) es una ley general de equilibrio de todos los sistemas, sean sociales 0 de cualquier otro tipo.

Toda organización consiste precisamente en el desarrollo de alguna forma de autorregulación por feed-back negativo. No se conoce ningún sistema físico o biológico capaz de autorreproducirse, en el que la aparición de una respuesta a reacción positiva no esté integrada en un marco general a reacción negativa (cf. Guillaumaud,
1965-82). Afirmar que un sistema está autocontrolado por un feed-back negativo es otra forma de decir que persiste en el tiempo. Se comprende que esta afirmación, aplicada a la sociedad, ya era conocida.

\section{c) Confusión de equilibrio $y$ estabilidad en la teoria funcionalista.}

Los sociólogos funcionalistas se están ocupando en la traducción de los conceptos funcionales en términos de autorregulación. Este trabajo se explica, a nuestro juicio, porque el concepto de retroacción implica que el propio sistema engendra la antitesis del fenómeno que lo altera, y además, que el sistema asimila la antitesis, logrando perdurar gracias al ajuste entre la desviación y la contradesviación. Si todos los procesos sociales generan en la salida respuestas tan intensas como sea preciso para reaccionar a la intensidad de los estímulos en la entrada, la organización social adecuada debe imitar un servomecanismo ${ }^{19}$. El ajuste sería una condición de la estabilidad social, y no un juicio de valor.

Nos parece que los funcionalistas confunden dos procesos que están efectivamente relacionados, pero cuyas diferencias para los sistemas sociales son transcendentales: la reproducción del equilibrio y de la estabilidad:

- El equilibrio se refiere a la reproducción de la organización estructural del sistema.

19 De la intracausación se pasa fácllmente a la hipótesis dogmática de la primacía del equilibrio como condición de la reproducción social. Un estado que está completamente determinado por la interrelación de todos sus elementos sólo puede variar por lo que $\mathrm{Pa}$ reto llama ufactores artificiales", es declr, por la destrucción del sistema causada por algún accidente exterior a su proplo estado. 
- La estabilidad se refiere a la perduración de la totalidad del sistema en el tiempo, conservando o no la misma estructura.

El equilibrio social está garantizado por la retroacción negativa. La estabilidad social está garantizada por la adopción alternativa en el momento oportuno de retroacciones positivas y negativas. Los funcionalistas suponen que el equilibrio del sistema social supone su estabilidad, cuando to cierto es el razonamiento inverso: un sistema estable será equilibrado, pero no todo sistema equilibrado será estable.

\footnotetext{
Por efemplo: los psiquiatras han puesto de manifiesto las diferencias que existen entre equilibrio y estabilidad, estudiando las relaciones sociales entre el esquizofré. nico y su familia. La existencia del esquizofrénico es esencial para el equilibrio do la familia, de tal manera que el sistema (familia-entermo) reacclona contra la rotura de los bucles retroactivos que les ligan, oponiéndose a la cura. Sin embargo, es evidente que el sistema no es estable (cf. Laing, 1970).
}

En teoría social debe distinguirse entre la homeostasis como medio, y la homeostasis como fin. Si la homeostasis es el medio del equilibrio no es evidente el fin de la sociedad (cf. Davis, $1965,8 / 13$ ). La rotura de los servomecanismos que lo regulan es la única forma posible que tiene un sistema social de recuperar la estabilidad cuando las condiciones del medio se han alterado.

\section{d) El "feed-back" por sí so- lo no garantiza ni la con- tinuidad, ni la viabilidad del sistema.}

La perpetuación de un sistema social requiere a veces la adopción de un nuevo feed-back, que genera nue- vas pautas de respuesta. Se ofrece un ejemplo actual en la inversión de los criterios de moralidad sexual a partir de la aparición de los anticonceptivos. La supervivencia de la totalidad del sistema puede exigir que se reestructure la organización del sistema hasta producir una mutación del mismo. Estas mutaciones no sólo son respuestas adaptativas a situaciones revolucionarias. Pueden surgir de procesos inmanentes a las propias leyes del sistema. A veces, la mutación emerge cuando se hace explícita una función contenida en el código (genético o informacional) de la es. tructura del sistema. Por ejemplo, el paso de la fábrica industrial a la fábrica automática se puede considerar como la emergencia de una cualidad genética, ligada a la racionalización propia del sistema de producción capitalista. Es evidente que la reproducción de este sistema de producción ha requerido la desorganización de los primitivos equilibrios (sobriedad, ahorro, ascética del trabajo, etc.) y la estructuración de relaciones nuevas (ostentación, tiempo libre, consumo, erotismo, etc.). Este tipo de emergencias son, según Monod, una revelación y no una creación (cf. 1970-102).

\section{LA REPRODUCCION DEL SISTEMA EN LOS PROCESOS SOCIALES}

\section{a) Integración de la estabi- lidad y del cambio.}

El análisis de sistemas trata de comprender cómo se reproduce la sociedad. En este empeño coincide con el funcionalismo. Su teoría se diferencia de la funcionalista porque interpreta que la estabilidad de la sociedad no requiere obligatoriamente ni el equilibrio del sistema, ni la reproducción del modelo social; y porque considera que la reproducción no puede ser separada de la mutación. 
La teoría marxista del cambio se integra como la reproducción social que se caracteriza por una mutación que destruye las antiguas formas de organización. En el aspecto operacional, esta perspectiva ha sido bien aclarada por Guillaumaud (1965).

El estudio diacrónico del sistema se denomina «análisis de la reproducción social y debe tener en cuenta al mismo tiempo los aspectos invariantes y los aspectos mutantes. Los invariantes podrán objetivarse en un programa (donde existe continuidad existe un modelo), y su función incluye que el comportamiento del sistema en algún momento alterará el propio programa (donde hay actividad, hay alteración).

\section{b) Concepto sociológico de reproducción.}

La teoría de la reproducción social propone una sintesis que quiere cerrar la polémica entre consensualistas y conflictivos, funcionalistas y dialécticos. Esta intención se muestra, por ejemplo, en la definición de reproducción que facilita Barel: «Forma particular de combinación de la invarianza y del cambio, en la cual la invarianza es necesaria para el cambio, y viceversan (1973-153).

El término reproducción ha entrado en la literatura sociológica por medio de Marx. Los funcionalistas, llevados de un biologismo que les viene de Spencer, redujeron su primitivo uso intencional a un uso adaptativo. De hecho los funcionalistas se han centrado en el estudio de una de las formas de la reproducción: la persistencia de sistemas no-mutantes. Esta elección les ha llevado a identificar el concepto de función como los requisitos de la supervivencia del sistema. Se ha señalado frecuentemente que este enfoque es conservador; pero sobre todo es una concepción de la función muy parcial.

\section{c) Formas y funciones de la reproducción en los sis- temas sociales.}

La teoría de los sistemas muestra que la reproducción social satisface numerosas funciones, además de atender al «social survival». El repertorio de formas de reproducción es muy amplio. Proponemos una síntesis poslblemente incompleta, pero que muestra cuantas nuevas direcciones se abren al análisis:

- Reproducción como desplazamiento. El sistema de orden jerárquico militar se ha replicado en el sistema de producción industrial, según Veblen (1911); como anteriormente la organización civil del estado romano, se reprodujo en la iglesia medieval (cf. Hegel, 1968).

- Reproducción como multiplicación. Las relaciones formales, características del sistema de cambio en el mercado, se reproducen en las relaciones sociales como libertal formal y en el derecho como igualdad formal, según Marx.

- Reproducción como difusión del programa.-Una de las posibles formas de reproducción que adopta un sistema social consiste en el control de otros. El modo de producción y la organización del consumo característicos de las sociedades industriales se generalizan en organizaciones sociales muy diferentes de aquellas en las que tuvieron su origen. El difusionismo puede ser rehabilitado en ciencias sociales, porque postula el acoplamiento entre dos sistemas distintos, de los cuales uno controla al otro; y no necesariamente la imitación ni la asimilación.

El acoplamiento en serie asimila el sistema controlado mediante su previa desestructuración, como ha ocurrido, por ejemplo, en Tahití. Sin embargo, la penetración de un programa extraño no siempre destruye los códigos 
sociales propios. La sociedad japonesa muestra la resistencia de su cultura a la desorganización por el modelo industrial. Este ejemplo de difusión tiene que explicarse empleando un modelo de acoplamiento en retroalimentación.

- Reproducción como traslación de nivel.-La teoría de sistemas observa que, en el sistema social, hay un paso de la energía a la información, por ejemplo, cuando la represión interiorizada sustituye a la represión externa; y de la información a la energía, por ejemplo, cuando la cultura se muestra como una fuerza productiva [cf. Marcuse, 1970 a).

- Reproducción como diferenciación. La reproducción de la fuerza de trabajo en el proceso histórico de la industrialización ha diferenciado el subsistema de los empleados de cuello blanco, del subsistema de los asala. riados (según $W$. Mills, 1957). La industrialización no ha producido la integración de los asalariados en una clase proletaria unitaria, poseedora de la misma conciencia y de intereses de clase comunes. De tal forma que la división del trabajo, según este autor, cumple una función integradora como había indicado Durkheim (1967-30, 147); y al contrario de lo que aguar. daba Marx.

- Reproducción como explicitación.Comte había predicho la aparición de nuevos roles: para el científico como "tecnócrata" (1972 d, 147), y para la mujer religiosa como aglamour " (1912II, 203). Los nuevos papeles ya estaban implícitos en el sistema de producción industrial, en un momento en el que todavia la imagen del científico se definía por la neutralidad, y la de la mujer por la discreción erótica (cf. 1893-86).

- Reproducción como mutación.-Cada vez que la composición orgánica del capital disminuye se repite uno de los ciclos en los que se produce una expropiación de los pequeños industriales en beneficio de las empresas más grandes, según Marx (1956-55, seq.). El último ciclo, y la última acumulación, consistirá en la expropiación de los titulares privados del capital. La socialización de los bienes de producción producirá un cambio cualitativo de los procesos sociales. La reproducción de la sociedad será dialéctica, en vez de cíclíca. Al cíclo [expansión-regresión] sustituirá la dialéctica [satisfacción de la necesidad presente, superación de la necesidad, creación de la necesidad]. Esta forma de mutación equivale a la generación de un nuevo programa de control del sistema (cf. A. C., 1956-85 seq.).

\section{ANALISIS DE LA DIFERENCIACION SOCIAL}

\section{a) La diferenciación social se explica por más de un sistema de orden.}

La diferenciación social es otra forma de referirse a la complejidad, o a la existencia de un orden.--La existencia de alguna diferenciación interna entre los componentes es consus. tancial con la idea de sistema. Todo sistema complejo está diferenciado, pero no es necesario concluir que la diferenciación del sistema procede de un único criterio de orden. La organización diferencial del sistema que aparece como más relevante tiene que ver con el punto de vista teórico que elige el sociólogo. Moles (1968) muestra que en cualquier organización coexisten al menos dos sistemas de orden: una diferenciación funcional y otra estructural. Por ejemplo (proponemos nosotros), un equipo de investigación sociológica puede diferenciarse funcionalmente por los distintos trabajos que llevan a cabo sus miembros; y al mismo tiempo cabe establecer una diferenciación estructural, distinguiendo entre los distintos espe. cialistas que cooperan en el equipo. 


\section{b) La sociedad es un objeto pluridimensional.}

La diferenciación social se expresa generalmente como la ubicación de los componentes del sistema en niveles distintos.-Esta forma de diferenciación es válida para explicar tanto el sistema estructural como el proceso funcional. El análisis de sistemas rechaza la hipótesis funcionalista de que una dependencia entre dos componentes del sistema significa siempre que ambos se encuentran en un mismo nivel.

La concepción funcionalista de la integración social es, frecuentemente, contraria a la realidad, porque un sistema diferenciado tiende a ser pluridimensional, especialmente si sus componentes son objetos sociales. Pero, sobre todo, es innecesaria. Un sistema pluridimensional también es un sistema integrado; sólo que para explicar su reproducción es necesario referirse a criterios de integración que, a su vez, son pluridimensionales.

Las dificultades que encuentra el análisis estructural funcional no proceden de las conexiones que establece entre componentes cualitativamente distintos (por ejemplo, valores y comportamientos); surgen de que postula la existencia de un mismo plano para aquellos componentes que son interdependientes, como consecuencia de su dependencia. Este supuesto se encuentra, por ejemplo, en el análisis de estructuras latentes de Lazarsfeld (cf. 1950).

\section{c) Diferenciación jerárqui- ca: análisis de la domina. ción.}

Mesarovic y colaboradores muestran que cuando un sistema social aparece organizado en una pluralidad de ni- veles, generalmente unos seleccionan a otros. La organización y el funcionamiento de los subsistemas que pertenecen a un nivel, dependen del funcionamiento y la organización de los subsistemas que ocupan un nivel dominante.

Cabe interpretar este tipo de relación asimétrica aen pirámide. como una diferenciación jerárquica del sistema $(1970-34,215)$.

Algunos sociólogos afirman que la diferenciación jerárquica es una forma de orden estructurante, antes de ser un orden estructurado en el interior del sistema. Por ejemplo, Goldmann interpreta la forma que adoptan las relaciones sociales de dominación en una sociedad como el efecto de un subsistema especializado en la estructuración del conjunto (1959-995). La idea es antigua y vuelve a la teoría social con cierta frecuencia: la burocracia, la clase ociosa, las élites ascendentes, han sido descritos como los niveles diferenciados que, desde distintos puntos de vista (la organización, el poder, la innovación) conforman sistemas y procesos sociales. El análisis de sistemas aporta como novedad un método de análisis. Explora con modelos cibernéticos las relaciones existentes entre el funcionamiento del subsistema (los leadings parts de la sociedad) y la organización en el interior del sistema estructurado (Por ejemplo, ejército, Iglesia, etcétera) ${ }^{x}$.

\section{d) La dominación es disimé- trica pero no unidirec- cional.}

Como los niveles jerárquicamente superiores determinan la forma de estructuración de los niveles inferiores, controlan la estabilidad del subsistema dependiente. Por ejemplo, la jerarquía

¿ Sobre los métodos, cf. Barel (1971). 
de las profesiones está en parte controlada por la profesión que expende títulos académicos de capacitación. Las instituciones académicas pueden alterar la jerarquía profesional cambiando los contenidos de la enseñanza, el rigor de las pruebas, etc. Pero cualquier nivel diferenciado en el interior de un sistema posee (por definición de la diferenciación), una cierta autonomía. En el ejemplo propuesto, las actividades específicas que definen cada profesión, la jerarquización interior de sus miembros, etc., suelen ser actividades autónomas respecto al control por los títulos (aunque puedan estar controlados por otros niveles del mismo sistema).

El subsistema aintervenido» por otro, le somete su estructura. Pero el sistema.global depende para sobrevivir de la actividad autónoma que desarrollan los niveles inferiores. La conformación que el nivel estructurante impone al sistema tiene que ajustarse al comportamiento de los niveles inferiores, estableciendo circuitos de feed-back negativos. El controlador que no acepte ser controlado desorganiza el sistema.

Por otra parte, la reproducción de la dominación supone la autonomía parcial de los niveles dominados. De este modo el sístema asegura su adaptabilidad a las cambiantes circunstancias de la realidad. La necesidad que tiene el sistema de ajustarse al cambio de las circunstancias, requiere que el programa del control posea la flexibilidad necesaria para tolerar respuestas "desviadas". Se concluye que todo sistema de dominación, en cuanto parcialmente autónomo, es un sistema parcialmente indeterminado (cf. Buckley, 1967).

\section{e) Las formas generales de integración.}

Un șistema se describe por su forma de diferenciación, pero se postula por su cohesión, es decir, por la capacidad de responder coherentemente a las demandas 0 estímulos del medio.
Existen dos formas de estructuración (cf. Watzlawick et alt, 1967-2, 62):

Estructuración complementaria: Tiende a maximizar la diferencia entre los niveles que separan a los componentes del sistema.

Estructuración simétrica: Tiende a minimizar la diferencia entre los componentes, los cuales se situarán frecuentemente en el mismo nivel.

Los sistemas que funcionan mediante una especialización interior de funciones son del tipo complementario. La diferenciación jerárquica es una de las formas posibles de funcionamiento que puede adoptar un sistema complementario ${ }^{21}$.

El hecho de que los componentes de un sistema sean simétricos no significa que el sistema sea necesariamente consensual (por ejemplo, las relaciones entre los actores de un duelo son simétricas). Frecuentemente un sistema simétrico es muy conflictivo. Se encuentra con frecuencia esta última forma de estructuración en la familia, por ejemplo, cuando se estudian los conflictos maritales y paterno-filiales (cf. Cooper, 1972; Mendel, 1972). Laing ha descrito un impresionante repertorio de acoplamientos simétricos en las relaciones entre dos personas neuróticas (1971). EI análisis de la enfermedad con el método de los sistemas ha puesto de manifiesto las relaciones simétricas que ligan al enfermo mental y a la sociedad que lo rodea: ha establecido que el sistema al que pertenece la locura no es el clínico, sino el social (cf. Foucault, 1964; Laing, 1970; Basaglia; 1973). El movimiento conocido como antipsiquiatría no es otra cosa que la restitución de la enfermedad mental al sistema social, a partir de la aplicación del método de análisis sistemático ${ }^{22}$.

21 La diferenciación jerárquica parece ser la forma más frecuente de diferenciación estructural en el campo del organismo biológico y de la socledad, pero no es la forma más general.

2. El fracaso de la psiquiatría de orientación científico-natural en el esclarecimiento de las causas" de los síntomas ha llevado 


\section{f) Génesis de nuevas for- mas de diferenciación.}

Todos los componentes diferenciados del sistema social no están necesariamente vinculados. El análisis de sistemas acepta la presencia de componentes "libres». Son elementos alibres $:$ : el hippye en el sistema de producción de la sociedad sobreproductora; el alienado en la sociedad medieval; el bramin en la sociedad india. En los procesos de readaptación social, los elementos libres tienen la probabilidad de generar nuevas formas de diferenciación social. Integrados en un nuevo subsistema pueden terminar saliéndose del sistema; o concluir situándose en algún nivel en el interior del sistema global, sin excluir el nivel de control. Este análisis trae a la mente la teoria del reclutamiento de las élites de Pareto, y efectivamente. Pareto ilustra su modelo con temas sociales y momentos históricos en los que existen numerosos elementos libres (cf. 1967-68 seq.).

\section{g) Los nuevos métodos de análisis de la diferencia. ción.}

El análisis de sistemas está vertido al desarrollo de métodos que permitan captar la complejidad del sistema social como la diferenciación entre planos. La investigación se orienta actualmente en dos direcciones: se están explorando métodos semiológicos, especialmente en psiquiatría, antropología y media; por otra parte, se están probando métodos cibernéticos, especialmente en sociología del conocimiento, psicología social y sociología del cambio y la reproducción social.

a los psiquiatras a preguntarse por los efines.. El síntoma se interpreta como una regla de juego entre el enfermo y su contexto famlliar o social (en lenguaje cibernético, equivale a una redundancia).

\section{BIBLIOGRAFIA CITADA}

ADLER, A.: El carácter neurótico. Buenos Alres, Paidós, 1954.

ARON, R.: Dieciocho lecciones sobre la sociedad industrial. Barcelona, Seix Barral, 1964.

ASHBY, W. R.: Introducción a la clbernética. Buenos Aires, Nueva visión, 1960.

BAREL, Y.: "Prospective et analyse de Systèmes:. La documentation française. Paris, 1971.

- La reproduction sociale. París, Anthropos, 1973.

BASAGLIA, F.; et BASAGLIA, F.: La mayoría marginada. Barcelona, Laia, 1973.

BERTALANFFY, L. V.: General System theory, foundations, development, applications. $\mathrm{N}$. Y. G. Braziller, 1969.

BOUDON, R.: A quoin sert la notion de «structures? Paris, Gallimard, 1968.

BOUTHOUL, G.: Les structures sociologiques. París, Payot, 1968.

BUCKLEY, W.: Society and modern systems theory. N. J. Prentice Hall inc, 1967.

COMTE, A.: "Discours sur l'esprit positif , en Traite d'astronomie populaire. Paris, Apostolat positiviste, 1893

- Système de politique positive. París, G. Grés et Cni, 1912.

- Cours de philosophie positive», en La Science Sociale. París, Gallimard, 1972.

COOPER, D.: Mort de la Famille. París, du Seuil, 1972.

DAVIS, K.: La sociedad humana. Buenos Aires, Endeba, 1965.

DELPECH, L. J.: La cybernétique et ses théoriciens. París, Casterman, 1972.

DURKHEIM, E.: Las reglas del método sociológico. Buenos Aires, Dédado, 1964. - De la división del trabalo social. Buenos Aires, Schapire, 1967.

FISBURN, P. C.: Les mathématiques de la décision. Parls, Gauthier Villars, 1973.

FORTET et LE BOULANGER: Eléments pour une synthèse sur les systèmes à autoorganisation. París, Bol. Metra, núm. 12, 1967.

FOUCAULT, M.: Histoire de la folie à l'âge classique, París, Plon, 1964.

FRISCH, K. V.: Vie et moeurs des abeilles. Paris, Albin Michel, 1969.

GOBINEAU, A. de: Essai sur l'inégalité des races humaines. París, P. Belfond, 1967.

GOLDMANN, L.: Recherches dialectiques. París, Gallimard, 1959.

GUILLAUMAUD, J.: Cybernétique et matérialisme dialectique. París, Editions Sociales, 1965.

GUILlauME, P.: Psicología de la forma. Buenos Aires, Psique, 1964.

GURVITCH, G. et alt.: Sociologie, París, Presses Universitaires, 1962. 
HEGEL, G. F.: Filosofía del Derecho, Buenos Aires, Claridad, 1968.

HJELMSLEV, L.: Essais Linguistiques. París, Minuit, 1971.

HUANT, E.: Du biologlque au social. París, Dunod, 1957.

- L'appllcation de la cybernétique aux mécanismes économiques. París, E.M.E., 1967.

HUSSERL, E.: Ideas. México, D. F., Fondo de cultura económica, 1962.

JACOB, F.: La logique du vivant. París, Gallimard, 1970.

KOESTLER, A.: Le cheval dans la locomotive. París, Calmann Levy, 1968.

KOSIK, K.: La dialectique du concret. Paris, Maspero, 1970.

LAING, R. D.: Le mol divise. París, Stock, 1970.

- Knots. París, Stock, 1971.

LAZARSFEL, P. F.: . The logical and mathematical foundation of latent structure analysiss, en S. A. Stouffer et alt: Measurement and Prediction. Princ., Univ. Press, 1950.

LEFEBVRE, H.: Logique formelle. Logique dialectique. Paris, Anthropos, 1969.

LEVI-STRAUSS, C.: Arte, lenguaje, etnologia. México, D. F., Siglo XXI, 1968.

- Tristes trópicos. Buenos Aires, Eudeba, 1970.

LEWIN, K.: Psychologie Dynamique. París, Presses Universitaires, 1964.

MARCUSE, H.: Ensayos sobre politica y cultura. Barcelona, Ariel, 1970.

MARTIN SERRANO, M.: Comte, el Padre negado. México, D. F., Fondo de Cultura Económica (en prensa), 1975.

MARX, K.: El Capital, tomo V: *Historia crítica de la teoría de la plusvalían. Buenos Aires, Cartago, 1956.

- Los fundamentos de la critica de la economia politica. Madrid, A. Corazón, 1972.

MENDEL, G.: La révolte contre le père. París, Payot, 1972.

MESAROVIC et alt.: Theory of hlerarchlcal multilevels systems. N. Y., Academic Press, 1970.

MICHETTE, A.: La perception de la causalité. Lovaina, Publicat. Univ., 1954.
MILLS, C. W.: La Imaginación sociológica. México, D. F, Fondo de Cultura Económica, 1957.

MOLES, A.: Méthodologie vers une science de I'action. París, Gauthier, 1964.

- Théorie de l'information et perception esthétique. París, Denoël, 1972.

- Le dossier de la cybernétique. Paris, Marabout, 1968.

MONOD, J.: Le hasard et la nécessité. París, Seuil, 1970.

NADEL, S. F.: La théorie de la structure soclale. París, Minuit, 1970.

NEUMANN, J. $\mathrm{V}$., et MORGENSTERN, 0 . The theory of games and economic behavior. Princ., Univ. Press., 1953.

PARETO, V.: Forma y equilibrio sociales. Madrid, Revista de Occidente, 1967.

PARSONS, T.: La estructura de la acción social. Madrid, Guadarrama, 1968.

PIAGET, J.: Biologie et Connaissance. París, Gallimard, $1967 \mathrm{a}$.

et alt.:

- Logique et connaissance scientiflque. París. Gallimard, $1967 \mathrm{~b}$.

- Tendencias de la investigación en las clencias sociales. Madrid, Allanza, 1970.

POPPER, K.: The poverty of historicism. Londres, Routledge and Kegan, 1957.

SARTRE, J. P.: Crítica de la razón dialéctica. Buenos Aires, Losada, 1963.

SCHAFF, A.: Histoire et Vérité. Paris, Anthropos, 1971.

SCHOPENHAUER, A.: Los dos fundamentos de la ética. Buenos Aires, Aguilar, 1965.

TÖNNIES, F.: Gemelnschaft und gesellschaft. Leipzig, Fues's Verlag, 1887.

TOURAINE, A.: Sociologie de l'action. París, du Seuil, 1965. - La société post industrielle. Paris, Denoël, 1969.

VEBLEN, T.: The place of science In modern civilization. N. Y., B. W. Huebsch, 1911. - Teoria de la clase ociosa. México, D. F., Fondo de Cultura Económica, 1964.

WATZLAWICK et alt.: Pragmatics of Human Communication. N. Y., W. W. Norton, 1967.

WIENER, N.: Cibernetics. París, Hermann, 1948. - Cybernétique et société. París, Union Générale d'Editions, 1971. 


\title{
Reseña de «Aplicación de la teoría y el método sistemático en ciencias sociales»
}

\author{
Yves BAREL
}

Reproducida en Anthropos, nº 41-42, 1984

\begin{abstract}
"La nueva lógica de los sistemas se pretende presentar por sus teóricos como el primer método universal que abarca igualmente el mundo físico, orgánico y social. La identidad del método preservaría no obstante la diversidad de los objetos. La sociedad puede ser analizada como un sistema; el organismo también, y también la máquina y la propia naturaleza; aquí se detienen las analogías legítimas”

El autor muestra que la teoría de sistemas emparenta con los estructuralistas y con los dialécticos porque está interesada en establecer los diferentes estados posibles que puede adoptar el sistema social; lo cual les aleja de los positivistas; y se relaciona con los sociólogos del conocimiento (fenomenólogos) porque entiende que la significación de los datos sociales se refiere a la teoría sistemática que sirve para organizarlos: lo cual les separa de los empiristas.
\end{abstract}

Según el autor, la teoría de sistemas retoma el intento prematuro de Comte para establecer un método general que relacione el sistema social con el cognitivo; y asume, desde una nueva perspectiva cibernética, la afirmación de Marx de que toda teoría sobre el sistema social equivale a un instrumento de control sobre ese sistema.

A partir de esta contextualización, el Autor aplica el propio método sistemático para ofrecer una exposición de la teoría de sistemas. El artículo identifica los postulados sistémicos y los organiza como una estructura axiomática, señalando en cada ocasión la conexión que existe entre esos postulados y las teorías sociológicas clásicas. Expone el uso metodológico que se ha hecho del concepto de "fin" y del de "causa” para explicar las estructuras sociales. Describe en torno a las nociones de azar, determinismo y finalismo, las relaciones existentes entre libertad y constricción, a nivel de las organizaciones y de los comportamientos Señala que la cibernética retoma de la dialéctica que los procesos sociales son irreversibles, en relación con el análisis del feed-back negativo. Los criterios sistemáticos de orden y de entropía, sirven para explicar la reproducción del nivel elevado de complejidad que caracteriza a las organizaciones sociales; un tema que fascinó a los autores clásicos (Comte, Lévi-Strauss, entre otros)

El artículo analiza la aplicación de los conceptos de sincronía y diacronía al estudio de la evolución de los sistemas abiertos y cerrados; y se detiene en los modelos de funcionamiento social que operan con los criterios de equilibrio y de estabilidad. Así se enlaza con el problema de las formas de reproducción y diferenciación de los sistemas sociales, ofreciéndose un modelo canónico que contiene un repertorio de posibles modalidades de perpetuación en el tiempo que presentan los sistemas sociales históricos. 